\title{
Experiments to increase the used Energy with the PEGASUS Railgun
}

\author{
S. Hundertmark, M. Schneider, D. Simicic, G. Vincent \\ French-German Research Institute of Saint-Louis \\ 68301 Saint Louis, France \\ Email: stephan.hundertmark@isl.eu
}

\begin{abstract}
The French-German Research Institute (ISL) has several railguns installed, the largest of these is the PEGASUS accelerator. It is a $6 \mathrm{~m}$ long, $4 \times 4 \mathrm{~cm}^{2}$ caliber distributed energy supply (DES) railgun. It has a $10 \mathrm{MJ}$ capacitor bank as energy supply attached to it. In the past, this installation was used to accelerate projectiles with a mass of about $300 \mathrm{~g}$ to velocities up to $2500 \mathrm{~m} / \mathrm{s}$. In the ongoing investigation, it is attempted to accelerate heavier projectiles to velocities above $2000 \mathrm{~m} / \mathrm{s}$. For this a new type of projectile including a payload section was developed. In this paper the results of the experiments with payload projectiles using a primary energy between $3.8 \mathrm{MJ}$ and 4.8 MJ are discussed.
\end{abstract}

\section{INTRODUCTION}

In the military domain, there are two main applications for a railgun. Both make use of the, compared to explosively driven guns, superior muzzle velocity being achievable. A long range electromagnetic artillery system can cover ranges up to $400 \mathrm{~km}$. Such a system would accelerate a heavy projectile with a mass of up to $60 \mathrm{~kg}$ to a muzzle velocity of $2500 \mathrm{~m} / \mathrm{s}$ [1]. Alternatively one can use the railgun to accelerate lighter projectiles in rapid succession to bring down approaching missiles in a last line of defense scenario. Both scenarios have the common requirement of a large muzzle velocity, but very different demands concerning the needed power levels and the design of the railgun itself.

At the ISL, PEGASUS is the largest railgun installation. This railgun has a primary energy storage of $10 \mathrm{MJ}$ and an overall efficiency of about $30 \%$. With the aim of reaching the desired $2500 \mathrm{~m} / \mathrm{s}$, the maximal total weight of the launch package has to stay below $1 \mathrm{~kg}$. Starting from this, different payload projectiles in the mass range of $600 \mathrm{~g}$ to $700 \mathrm{~g}$ were developed and tested. In a first series of investigations, a monolithic payload projectile was launched with primary energies ranging from $2.6 \mathrm{MJ}$ to $3.7 \mathrm{MJ}$, to velocities of up to $1560 \mathrm{~m} / \mathrm{s}$. To make better use of the primary energy and to investigate the innovative concept of a separating projectile, a projectile being split into two parts was designed. While the armature of the monolithic projectile consists out 4 rows of brushes in the rear half of the projectile, the separating projectile can leave the part of the projectile body with the 3 rearmost brush rows behind. At the same energy level of $3.8 \mathrm{MJ}$ the payload reached a velocity of $1825 \mathrm{~m} / \mathrm{s}$. A more detailed description of these experiments can be found in [2]. Here further modifications of the separating projectile and the experimental results with this type of projectile are described.

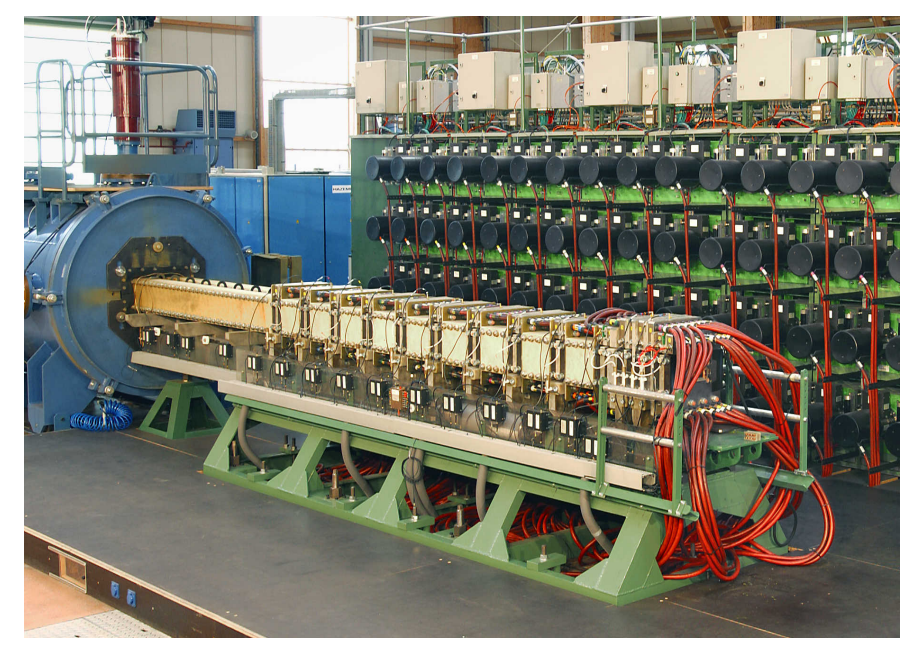

Fig. 1. Pegasus railgun facility.

\section{PEGASUS RAILGUN}

The PEGASUS railgun was built in 1998 with the goal to accelerate projectiles with masses of about $1 \mathrm{~kg}$ to velocities above $2000 \mathrm{~m} / \mathrm{s}$ in the medium caliber range $(40 \mathrm{~mm}$ to $50 \mathrm{~mm}$ ). Initially it was equipped with a glass-fiber and carbonfiber wound barrel with a caliber of $50 \mathrm{~mm}$ [3]. Figure 1 shows the PEGASUS installation with the currently mounted barrel, being in use since 2002 [4]. This barrel is $6 \mathrm{~m}$ long and has a square caliber of $40 \mathrm{~mm}$. A total of up to $10 \mathrm{MJ}$ of electrical energy can be stored in the 200 capacitor modules being visible in the background of the railgun. PEGASUS is a distributed energy supply (DES) system connected to 13 banks with 16 (the last one only 8) capacitor modules, each. Banks no. 1 and no. 2 are connected to the breech, the other banks are connected to current injection points being distributed along the first $3.6 \mathrm{~m}$ of the barrel length. For the purpose of the experiments being performed for this investigation, 4 capacitor modules in the banks no. 8 to no. 12 are disconnected. This reduces the capacity of these banks by $25 \%$ and the total capacity by $10 \%$. Each capacitor module can store up to $50 \mathrm{~kJ}$ and deliver a maximum current of $50 \mathrm{kA}$. They are equipped with a high-voltage capacitor, a thyristor, a crowbar diode and a pulse forming coil [5]. The electrical connection of the capacitor module to the accelerator is made with a coaxial cable. Due to the DES scheme the maximum total current that 


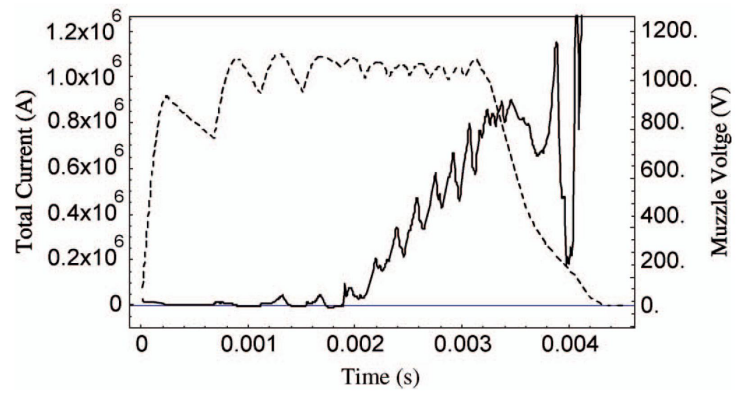

Fig. 2. Current (dashed line) an muzzle voltage (straight line) distributions for a high-velocity $(\mathrm{v}>2500 \mathrm{~m} / \mathrm{s})$ standard projectile shot (from [9]).

can be delivered to the gun is approx. 2 MA. The cylinder on the left hand side of figure 1 is a $7 \mathrm{~m}$ long catch tank, being equipped with several flash $\mathrm{x}$-ray tubes, Doppler radar devices and the possibility to mount several high-speed cameras. At the end of the free-flight phase in the cylinder, the projectile is stopped using steel plates.

\section{Pegasus Standard Projectile}

Since several years, projectiles used with the PEGASUS railgun are made out of glass fiber reinforced plastic (GRP) equipped with copper-fiber brush armatures. The GRP body of the projectile is lightweight, electrical isolating and relatively easy to manufacture. In combination with the copper brush armature, the current is confined to well defined paths through the projectile. In combination with appropriate sensors, this allows for the investigation of the current distribution in between different rows of brushes during launch conditions [6], [7]. The standard type of projectile, that was used in many investigations with PEGASUS, consists out of 8 brushes arranged in 4 rows. The total mass for this type of projectile is approx. $300 \mathrm{~g}$. The body of these projectiles is fabricated using industrial pre impregnated E-glass laminate. With these projectiles it was possible to reach velocities of about $2200 \mathrm{~m} / \mathrm{s}$, for higher velocities delamination and break-up of the GRP was observed [8]. One possibility to increase the velocity potential of plastic projectile bodies is to improve the stability against hard acceleration by using innovative materials. Experiments using a body composed out of alternating layers of GRP and carbon fiber materials allowed to reach a velocity well above $2500 \mathrm{~m} / \mathrm{s}$ [9]. In figure 2 the current and muzzle voltage trace for this shot is shown. The DES system of PEGASUS allows to generate a rather flat current pulse. Here, the current driving the projectile is just below 1.1 MA. The muzzle voltage trace shows that excellent sliding conditions exists until approx. $2 \mathrm{~ms}$. At that time the voltage increases rapidly, indicating the onset of transition. The peaks in the muzzle voltage signal, clearly seen in the raising part of the graph (between $2 \mathrm{~ms}$ and $3.5 \mathrm{~ms}$ ), are explained by inductive effects connected to the current injection locations of the DES system of the launcher [10]. Usually in experiment with PEGASUS, the plasma after transition appears in between one rail and the armature, only, while the other side of the projectile is pressed heavily against

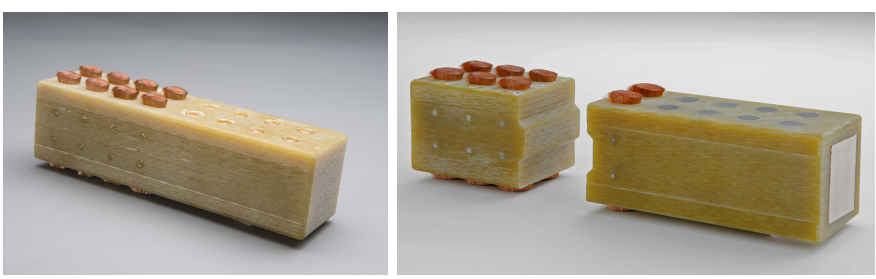

Fig. 3. Two versions of payload projectiles for the PEGASUS railgun.

the opposite rail. As long as the plasma is connected to the brushes and confined in the small space between projectile surface and rails, there is still a well defined current path and the clear pattern of inductive peaks as seen in the figure is visible. Underlying the peaks, there is a nearly linear rise of the muzzle voltage. This effect can be explained by an increase in resistance seen by the current flowing through the plasma and the copper brushes. Contributing to this resistance is the increase of the resistivity of the copper brushes due to the increase of the temperature and possibly a dilution effect of the plasma due to the rapid movement of the projectile.

\section{Payload Projectiles}

In figure 3 two different types of payload projectiles are shown. The projectile on the left hand side has a monolithic design, with a total mass of about $625 \mathrm{~g}$. The rear half of the $140 \mathrm{~mm}$ long projectile is identical to the standard projectile and carries 8 copper brushes in 4 rows. The forward part is equipped with 8 copper cylinders as payload. To reach higher velocities at the same electrical energy distributed to the launcher, the separating projectile seen on the right of figure 3 was introduced. The basic idea behind this type of projectile is, that during the acceleration the brushes are eroded rowwise from the rear to the front. Once the 3 rearmost brushes lost electrical contact to the rails, this part is left behind and only the payload section continues to be accelerated. The total mass and the dimensions for this projectile are the same as for the monolithic design. The forward payload part with the 2 booster brushes weighs approx. $400 \mathrm{~g}$. In [2] experiments with the monolithic projectile are described. A muzzle velocity of $1560 \mathrm{~m} / \mathrm{s}$ was reached using $3.8 \mathrm{MJ}$ of electrical energy. Accelerating a separating projectile using the same electrical energy resulted in a velocity of the payload section of $1825 \mathrm{~m} / \mathrm{s}$, an increase of $16 \%$ compared to the monolithic projectile design.

\section{EXPERIMENTS With SEPARATING PROJECTILES}

After the introduction of the separating projectile, several experiments with PEGASUS were performed, to investigate the behavior of this type of projectile. The primary electrical energy was increased from $3.8 \mathrm{MJ}$ to $4.8 \mathrm{MJ}$ and the brush diameter of the two booster brushes was changed from $8 \mathrm{~mm}$ to finally $10 \mathrm{~mm}$. The key parameters for the shot series are itemized in table [1. Figure 4 shows the current and the muzzle voltage traces for the shot no. 181. In addition to this, the velocity as derived from measurements of the projectile 


\begin{tabular}{|l|c|c|c|}
\hline$\#$ & El. Energy & Velocity & Booster brush $\varnothing$ \\
\hline 181 & $3.8 \mathrm{MJ}$ & $1825 \mathrm{~m} / \mathrm{s}$ & $8 \mathrm{~mm}$ \\
\hline 182 & $4.2 \mathrm{MJ}$ & $1880 \mathrm{~m} / \mathrm{s}$ & $8 \mathrm{~mm}$ \\
\hline 183 & $4.2 \mathrm{MJ}$ & $1945 \mathrm{~m} / \mathrm{s}$ & $9 \mathrm{~mm}$ \\
\hline 184 & $4.8 \mathrm{MJ}$ & $1820 \mathrm{~m} / \mathrm{s}$ & $9 \mathrm{~mm}$ \\
\hline 185 & $4.8 \mathrm{MJ}$ & $2170 \mathrm{~m} / \mathrm{s}$ & $10 \mathrm{~mm}$ \\
\hline
\end{tabular}

TABLE I

PARAMETERS OF THE SHOTS PERFORMED WITH THE SEPARATING PROJECTILE.

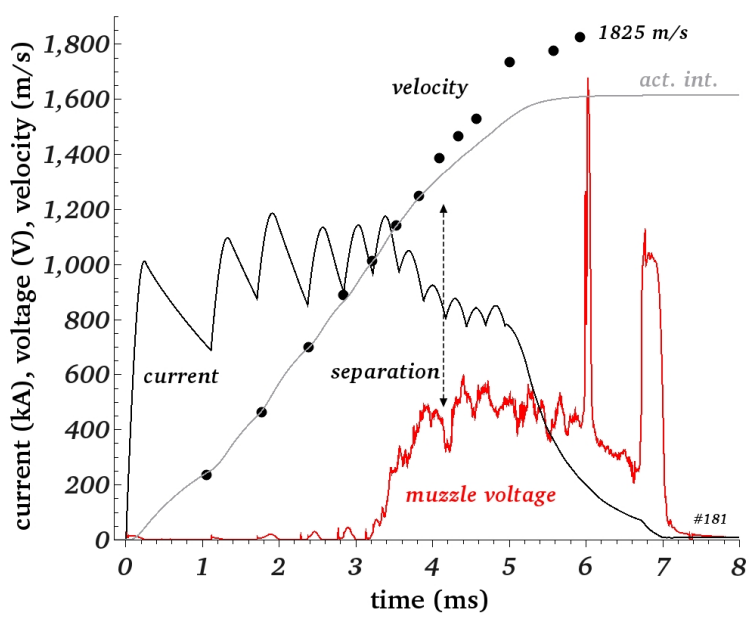

Fig. 4. Shot no. 181.

passage using B-dot sensors is shown using dots. The line label "act. int." represents a value that is proportional to the action integral $\left(\int \mathrm{I}^{2} \mathrm{dt}\right)$. The current reaches it's maximum value of $1.2 \mathrm{MA}$ at $1.8 \mathrm{~ms}$. The current drop after $3.5 \mathrm{~ms}$ is caused by the before mentioned capacity reduction of $25 \%$ for the banks no. 8 to no. 12. The muzzle voltage distribution shows that the projectile experienced excellent sliding contact until $3.4 \mathrm{~ms}$, when transition occurred. The voltage rises quickly to a plateau of about $500 \mathrm{~V}$ from $3.8 \mathrm{~ms}$ until the shot out of the payload part at $5.8 \mathrm{~ms}$. The voltage trace of this shot looks different to the trace from the standard projectile shot shown in figure 2 The inductive peaks and the linearly rising slope are not seen. The absence of the inductive peaks indicates, that the current is spread out over a larger area as compared to the standard projectile shot. The large rise of the muzzle voltage at $5.8 \mathrm{~ms}$ witnesses the shot out of the payload part of the projectile. Inspecting this peak closely, reveals that the peak is actually a double peak. The earlier sub-peak can be explained by current flowing through the copper cylinders (the payload) in the front of the projectile. Later at $6.6 \mathrm{~ms}$ a further peak appears. At that time, the rear part of the projectile leaves the barrel. The velocity of the projectile is measured, using bdot probes distributed along the barrel. Figure 4 shows that the measured velocity follows the action integral until approx. $4 \mathrm{~ms}$. After this time, the velocity rises stronger, than the action integral. This can be understood as the point in time, when the front part separates from the rear part, thus reducing the
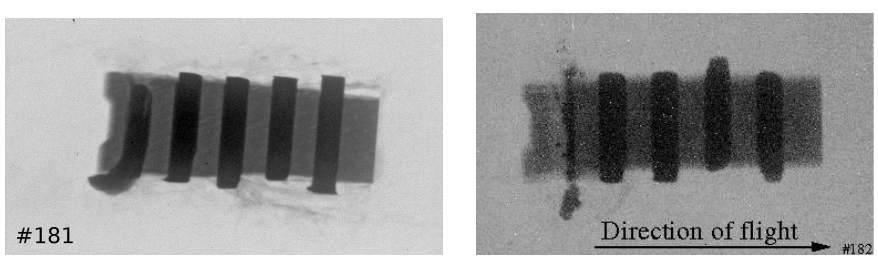

Fig. 5. X-ray picture of the payload part for shot no. 181 (left) and no. 182 (right).

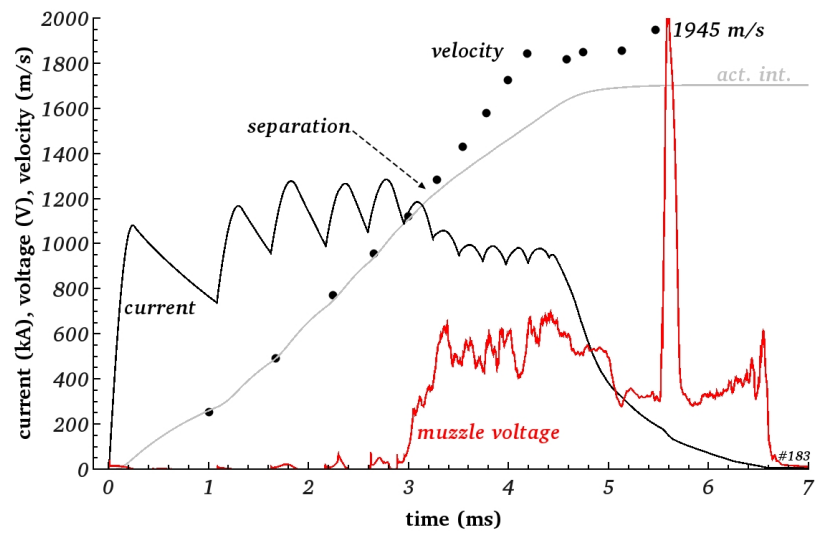

Fig. 6. Shot no. 183.

to be accelerated mass. For this shot, the velocity reached by the payload part is $1825 \mathrm{~m} / \mathrm{s}$. The x-ray picture in figure 5 (left) shows the payload part of the projectile during its free-flight in the blue catch tank. The movement is from left to right. The GRP body shows signs of delamination and the ends of the copper cylinders are exposed. They show clear signs of current conduction during the shot, thus supporting the discussion from above. In the next experiment, shot no. 182, the primary energy was increased to $4.2 \mathrm{MJ}$. The measured end-velocity of $1880 \mathrm{~m} / \mathrm{s}$ was less than expected. The freeflight x-ray picture 5 (right) shows that the booster brush is nearly fully eroded, indicating the development of a stronger plasma than in shot no. 181. As a consequence of this data, the decision was made, to increase the booster brush diameter to $9 \mathrm{~mm}$ and redo the experiment. The result of acceleration of this modified projectile is shown in figure 6 The muzzle voltage graph shows about the same behavior as in shot no. 181. After transition at $3 \mathrm{~ms}$, a plateau of approx. $500 \mathrm{~V}$ is reached. Muzzle exit of the payload part is at about $5.5 \mathrm{~ms}$. The measured velocity is $1945 \mathrm{~m} / \mathrm{s}$. Inspecting the trace being proportional to the action integral and comparing it to the measured velocity of the projectile, shows that the separation happened at approx. $3.3 \mathrm{~ms}$, just after the current injection no. 7. In shot no. 181, the projectile separated after injection no.9. A further increase of the primary energy to $4.8 \mathrm{MJ}$ in shot no. 184 resulted in the current and muzzle-voltage measurements shown in figure 7 . A peak current of more than $1.35 \mathrm{MA}$ is reached, but transition sets in early, at $2.5 \mathrm{~ms}$. In addition to this early onset, the voltage rises up to more than $800 \mathrm{~V}$ at about $3 \mathrm{~ms}$. This behavior is different to the behavior 


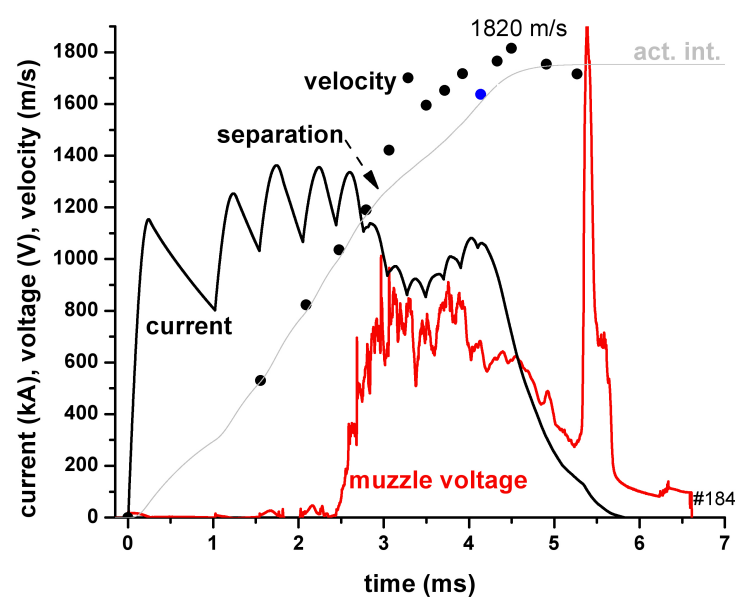

Fig. 7. Shot no. 184 .

seen in shots no. 181 and no. 183. The maximum measured velocity is reached at $4.5 \mathrm{~ms}$, before the projectile leaves the barrel. After this, the projectile decelerates until shot-out. Figure 9 (left) shows a strong material loss of the projectile body due to delamination. The copper cylinders had contact with the rails and where most likely conducting current. It is visible that the booster brush is moving out of its hole. Other $\mathrm{x}$-ray pictures showing the top view, witness, that the other brush is already lost before the $\mathrm{x}$-ray picture is taken. The movement and loss of the brush(es) is most likely the cause for the development of the large values of the muzzle voltage and the deceleration of the projectile in the final phase of the launch process. As the increase of the booster brush diameter was successful for shot no. 183, this strategy was attempted again, and its diameter was increased to $10 \mathrm{~mm}$. Figure 8 shows the key parameter traces of this shot. The current is again at about $1.35 \mathrm{MA}$ peak value. At $2.75 \mathrm{~ms}$ transition sets in, and until $3.2 \mathrm{~ms}$ the trace resembles very much the standard projectile behavior as shown in figure 2 . After $3.2 \mathrm{~ms}$ an approximate plateau of $600 \mathrm{~V}$ to $620 \mathrm{~V}$ is reached. The plateau is followed by a peak at $4.8 \mathrm{~ms}$ and shot out at $5.25 \mathrm{~ms}$. The split of the shot-out peak indicates that there was current conduction in the copper cylinders. The rear part of the projectile leaves the barrel at about $5.9 \mathrm{~ms}$, producing a peak in the muzzle voltage trace. The measured end-velocity for this shot is $2170 \mathrm{~m} / \mathrm{s}$. The trace for the action integral compared to the measured velocity shows, that separation occurred at about $3.5 \mathrm{~ms}$. This is again after current injection no. 7. The $\mathrm{x}$-ray picture in figure 9 (right) shows that the GRP holding the booster brushes is broken during acceleration, thus indicating, that the GRP holding the brushes is no longer able to cope with the forces during acceleration. For this reason a further increase in primary energy with this type of projectile was not attempted.

In figure 4 (shot no. 181) the muzzle voltage peak caused by the exit of the projectile from the barrel showed a sub-

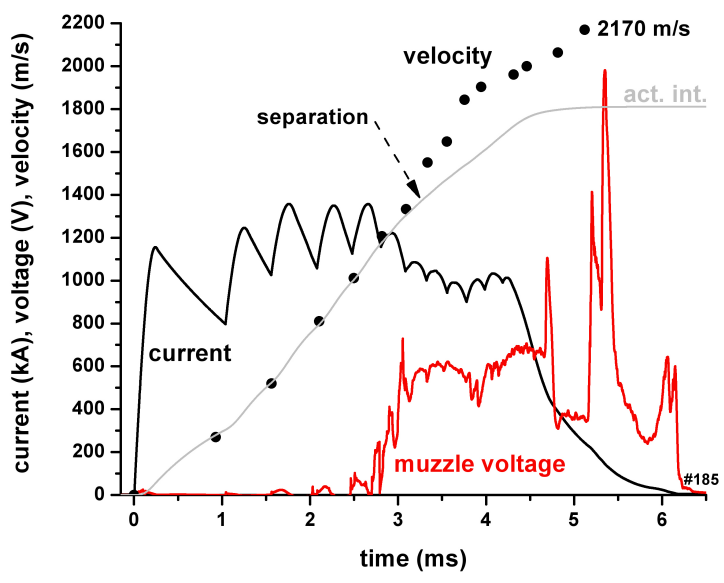

Fig. 8. Shot no. 185 .
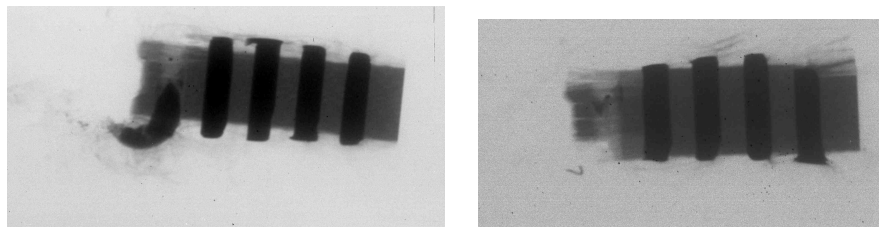

Fig. 9. X-ray picture of the payload part for shot no. 184 (left) and no. 185 (right).

structure. This sub-structure was interpreted as a sign for current conduction through the copper cylinders. Support for this hypothesis comes from the $\mathrm{x}$-ray pictures, that show exposed copper cylinders with signs of mechanical wear from sliding along the rails. In some of the figures one can also see the copper evaporating from the hot copper cylinders. As an example, this can be seen in figure 5 (left). For the projectiles used here, the copper cylinders are $16 \mathrm{~mm}$ apart (in direction of flight). The same distance holds for the brushes, as well. When a current carrying short circuit element like a brush or copper cylinder leaves the rails during shot-out, a plasma bridge will develop. This bridge connects the rail ends and the short circuit element. If another short circuit element is in-between the rails, the plasma bridge will eventually die out and the current will retract to this element. In figure 10 the muzzle voltage trace from shot no. 183 enlarging the time during the shot-out of the payload-part of the projectile is shown. Inspecting the raising slope from approx. $5.5 \mathrm{~ms}$ on, several small peaks on top of the slope are visible. The peaks are labeled with number 1 to 5. In the upper left corner, the x-ray picture of the projectile for shot no. 183 is shown. The direction of flight is from left to right. From right to left, the 4 rows of copper cylinders (labeled 1 to 4) and the booster brush (labeled 5) are visible. The muzzle voltage trace can be explained as follows. The payload-part of the projectile approaches the muzzle while the current drops rapidly (see figure 6). At the time of shot-out the current has approached a value of about $150 \mathrm{kA}$. While most of the current is flowing through the brush, some current 


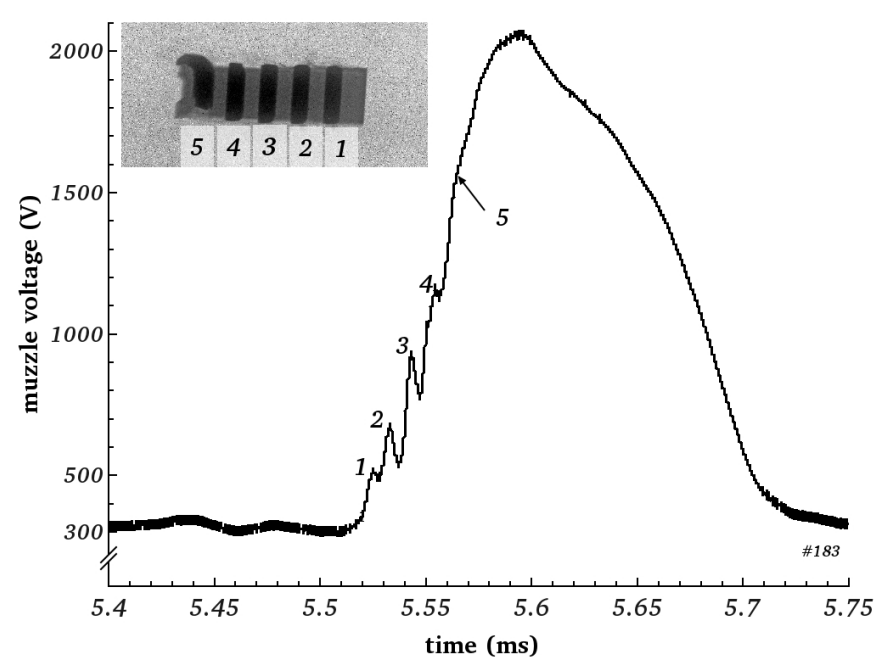

Fig. 10. Muzzle voltage for shot no. 183 at shot-out. This is a zoom-in of figure 6 The inset shows the $x$-ray picture of the projectile after it left the barrel.

is distributed in-between the 8 copper cylinders. When the cylinders with row number 1 leave the rails, a plasma bridge is established and the resistance increases. At the same the additional area bounded by the plasma bridge is filled by the magnetic field, thus generating an inducting effect. Due to this, the muzzle voltage raises. When the peak value of peak number 1 is reached the bridge breaks and the current switches back to the remaining current path still being in the barrel. During the time the current switches to the rearward short circuit path the muzzle voltage drops. Then the subsequent rows disconnect one after the other from the rails and the muzzle voltage peaks 2 to 4 are generated. When finally the booster brush leaves the rails, the plasma bridge has to carry the full remaining current. There is a slight change in slope, when the brush fully has ceased to make contact to the rails, as then the plasma bridge with a different resistance takes over. This point is labeled with number 5 in the figure. After this time a rising resistance due to the growing length of the plasma length continues to generate a rising muzzle voltage. At one point in time the current drops quicker than the resistance rises. For this shot this happens at approx. $5.6 \mathrm{~ms}$. In table II. the distances corresponding to the peak-to-peak time distance for a projectile with a velocity of $1945 \mathrm{~m} / \mathrm{s}$ are calculated. It is seen that the calculated values range between approx. $17 \mathrm{~mm}$ and $21 \mathrm{~mm}$. The actual distance from cylinder to the next cylinder (or brush) is $16 \mathrm{~mm}$. The hypothesis for the slightly larger derived value is, that the contact is not a solid copper to copper contact, but instead an plasma connection extending into the space around the cylinder. Overall, the muzzle voltage behavior in combination with the $\mathrm{x}$-ray picture gives evidence, that for this shot, the copper cylinders took part in establishing a short circuit route in-between the rails and were carrying current.

In table I 2 shots are listed with a primary energy of $4.8 \mathrm{MJ}$. The difference between these 2 shots is the diameter of the

\begin{tabular}{|l||c|c|c|c|c|}
\hline peak number & 1 & 2 & 3 & 4 & 5 \\
\hline time $(\mathrm{ms})$ & 5.5245 & 5.5332 & 5.5435 & 5.5535 & 5.5642 \\
\hline$\Delta \mathrm{t}$ to previous $\left(\mathrm{x} 10^{-5} \mathrm{~s}\right)$ & $\%$ & 0.87 & 1.03 & 1.00 & 1.07 \\
\hline$\Delta$ l to previous $(\mathrm{mm})$ & $\%$ & 16.9 & 20.0 & 19.5 & 20.8 \\
\hline
\end{tabular}

TABLE II

THE TIME FOR THE PEAKS LABELED 1 TO 5 IN FIGURE 10 IS LISTED. For TWO FOLLOWING PEAKS, THE TIME DIFFERENCE IS CALCULATED AND CONVERTED TO A DISTANCE BY USING THE PROJECTILE VELOCITY OF $1945 \mathrm{M} / \mathrm{s}$.

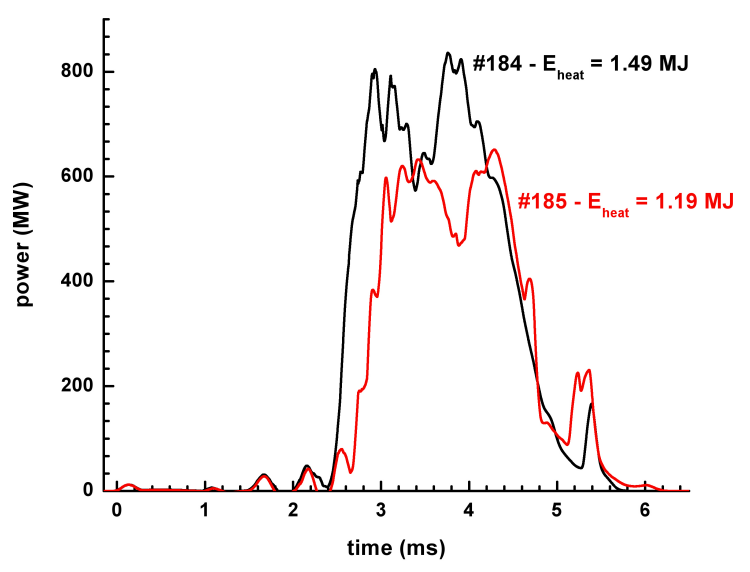

Fig. 11. Power across the rail-armature-rail contact for the two $4.8 \mathrm{MJ}$ shots (no. 184 and no. 185).

brush. While the first shot (no. 184) had a brush diameter of $9 \mathrm{~mm}$, shot no. 185 had this value increased to $10 \mathrm{~mm}$. The kinetic energy of the payload part (approx. $400 \mathrm{~g}$ ) was $663 \mathrm{~kJ}$ and $942 \mathrm{~kJ}$, respectively. Shot no. 185 has a payload part kinetic energy that is $279 \mathrm{~kJ}$ larger. In figure 11 the power acting on the rail-armature-rail interface is drawn. To suppress short time fluctuations as seen, for example, in the muzzle voltage trace, the curve was smoothed. Until $2.5 \mathrm{~ms}$, the onset of transition for shot no. 184, both curves are identical. The electrical power converted to heat during the acceleration at the rail-armature-rail contact element is very low, basically all the available electrical power at the rails is converted into acceleration of the projectile. After transition the heating power reaches values of up to $830 \mathrm{MW}$ for shot no. 184 and $660 \mathrm{MW}$ for shot no. 185. Integrating the power over time, results in the amount of energy that is converted into heat. This is $1.49 \mathrm{MJ}$ and $1.19 \mathrm{MJ}$ for shot no. 184 and shot no. 185 , respectively. The difference is $300 \mathrm{~kJ}$, very close to the $279 \mathrm{~kJ}$ difference in kinetic energy. This means that the additional available energy in shot no. 185 was converted to $90 \%$ into kinetic energy of the payload part of the projectile.

\section{Summary AND CONCLUSION}

During an investigation spanning over several years, different payload projectile types were designed and tested. In an earlier report [2] the experiments with an monolithic projectile 
and the development path to the separating projectile was described. Here experiments with a separating projectile type were presented. A series of 5 shots was made and for each shot the parameters, current, muzzle voltage, velocity and action integral were recorded. An inspection of the muzzle voltage traces of these shots revealed a very different behavior as compared to the muzzle voltage of the standard projectile with the same number of copper brushes. If the contact of the brushes to the rails is not disturbed by strong erosion or loss of brushes, the voltage raises after transition quickly to a plateau, while for the standard projectile, the voltage continues to increase. For shot no. 183 an enlarging of the shot-out muzzle voltage peak showed that the payload copper cylinders do take part in the sharing of the current. In addition to this, traces of molten copper smoke from the heat developed by current conduction and mechanical friction can be identified in some of the free-flight $\mathrm{x}$-ray pictures, pointing to the same conclusion. As the energy was increased, it was necessary to enlarge the brush diameter from $8 \mathrm{~mm}$ to $10 \mathrm{~mm}$. This indicates that there is a positive effect of a larger armature mass being available. One clear problem at the current PEGASUS railgun for experiments with velocities above $2000 \mathrm{~m} / \mathrm{s}$ is the delamination of the GRP projectile body seen in the x-ray photographs in the region where the payload is mounted and the inability of the GRP to adequately support the pushing booster brushes. As a consequence of this, the next design of the payload projectile will make usage of mechanically tougher materials. The currently preferred candidate material is aluminum.

\section{ACKNOWLEDGMENT}

The authors would like to thank for the professional support from the people in the workshop and from those working with the experiments in the experimental hall. This research was supported by the French and German Ministries of Defense.

\section{REFERENCES}

[1] I. R. McNab, S.Fish, F. Stefani, Parameters for an Electromagnetic Naval Railgun, IEEE Transactions on Magnetics, Vol.37, No.1, Jan. 2001.

[2] S. Hundertmark, M. Schneider, G. Vincent, Payload Acceleration Using a 10-MJ DES Railgun, IEEE Transactions on Plasma Science, Vol.41, No.5, May 2013.

[3] P. Lehmann, H. Peter, J. Wey, First experimental results with the ISL 10 MJ DES railgun PEGASUS, IEEE Transactions on Magnetics, Vol.37, No.1, Jan. 2001

[4] P. Lehmann, Overview of the Electric Launch Activities at the FrenchGerman Research Institute of Saint-Louis (ISL), IEEE Transactions on Magnetics, Vol.39, No.1, Jan. 2003.

[5] E. Spahn, G. Buderer, A flexible pulse power supply for EM- and ETClaunchers, 12th IEEE International Pulsed Power Conference, 1999. Digest of Technical Papers. Vol.2, 1999.
[6] O. Liebfried, M. Schneider, S. Balevicius, Current Distribution and Contact Mechanisms in Static Railgun Experiments With Brush Armatures, IEEE Transactions on Plasma Science, Vol.39, No.1, Jan. 2011.

[7] M.Schneider, R. Schneider, Measurement of the Current Distribution Between Multiple Brush Armatures During Launch, IEEE Transactions on Magnetics, Vol.45, No.1, Jan. 2009.

[8] C. Avril, D. Perreux, F. Thiebaud, B. Reck, S. Hundertmark, Development of Advanced Thermoplastic Composite Projectiles for High-Velocity Shots with the PEGASUS Railgun, IEEE Transactions on Plasma Science, Vol.39, No.12, 2011.

[9] B. Reck, P. Lehmann, E. Spahn, W. Wenning, M. D. Vo, A Model for Predicting Transition in Railgun Fiber Brush Armatures, IEEE Transactions on Magnetics, Vol.45, No.1, Jan. 2009.

[10] B. Reck, Mechanical behavior of the PEGASUS railgun projectile during the launch, IEEE Transactions on Magnetics, Vol.41, No.1, Jan. 2005. 